\title{
Schwann Cell Proliferative Responses to cAMP and Nf1 Are Mediated by Cyclin D1
}

\author{
Haesun A. Kim, ${ }^{1}$ Nancy Ratner, ${ }^{3}$ Thomas M. Roberts, ${ }^{2}$ and Charles D. Stiles ${ }^{1}$ \\ Departments of ${ }^{1}$ Microbiology and Molecular Genetics and ${ }^{2}$ Pathology, Harvard Medical School and the Dana-Farber \\ Cancer Institute, Boston, Massachusetts 02115, and '3epartment of Cell Biology, Neurobiology and Anatomy, College of \\ Medicine, University of Cincinnati, Cincinnati, Ohio 45267
}

In most mammalian cells, the cAMP-dependent protein kinase A pathway promotes growth arrest and cell differentiation. However in Schwann cells, the reverse is true. Elevated levels of cAMP function as the cofactor to a broad range of mitogenic cues in culture and in animals. Previous studies have suggested that cAMP acts at an early point in the Schwann cell mitogenic response, perhaps by stimulating the expression of growth factor receptors. We show here that cAMP acts downstream rather than upstream of growth factor receptor expression. The essential function(s) of cAMP is exerted as Schwann cells progress through the $G_{1}$ phase of the cell cycle. Ectopic ex-

In most mammalian cells, activation of the cAMP-dependent protein kinase A (PKA) pathway promotes growth arrest and cell differentiation. The antimitotic actions of cAMP reflect inhibition of the Ras/Raf/MAP kinase signaling pathway as a consequence of Raf phosphorylation by protein kinase A (Burgering et al., 1993; Cook and McCormick, 1993; Graves et al., 1993; Sevetson et al., 1993). Within Schwann cells, however, the relationship between cAMP and cell division is reversed. In cell culture, cAMP is an essential co-mitogen for a wide range of Schwann cell growth factors (Stewart et al., 1991; Jessen and Mirsky, 1992). For example, platelet-derived growth factor (PDGF), basic fibroblast growth factor (bFGF), insulin-like growth factor (IGF), and Reg-1 all promote Schwann cell growth, but only when they are added together with an ectopic source of cAMP or an agent that increases cAMP levels in the cells, such as forskolin (Davis and Stroobant, 1990; Eccleston et al., 1990; Stewart et al., 1991; Livesey et al., 1997). Thus, these growth factors can be considered as "incomplete" Schwann cell mitogens. Members of the neuregulin family of growth factors function as "complete" Schwann cell mitogens (Raff et al., 1978; Brockes et al., 1980; Lemke and Brockes, 1984). The neuregulins promote Schwann cell growth without the addition of ectopic cAMP or forskolin. However, neuregulins stimulate accumulation of endogenous cAMP within

\footnotetext{
Received Oct. 18, 2000; revised Nov. 21, 2000; accepted Nov. 22, 2000.

This work was supported by a postdoctoral fellowship from the National Multiple Sclerosis Society to H.A.K., National Institutes of Health Grant NIH-NS28804 to N.R., and NIH program project Grant HD24926 to T.M.R. and C.D.S. We thank Drs. Fred Gage and Theo Palmer (Salk Institute) for the pNIT retroviral vector, Dr. Richard Mulligan (Massachusetts Institute of Technology) for the 293 GPG retroviral packaging cell line, and Dr. Mark Marchionni (Cambridge NeuroScience) for the gift of rhGGF2. We also thank Drs. Zhimin Zhu, John Alberta, and Anita Bhattacharyya for helpful comments on this manuscript.

Correspondence should be addressed to Dr. Charles D. Stiles, SM1070, DanaFarber Cancer Institute, 1 Jimmy Fund Way, Boston, MA 02115. E-mail: charles_stiles@dfci.harvard.edu.

Copyright (c) 2001 Society for Neuroscience $0270-6474 / 01 / 211110-07 \$ 15.00 / 0$
}

pression studies using an inducible retroviral vector show that the $G_{1}$ phase requirement for cAMP can be alleviated by a single protein, cyclin D1. We show, in addition, that at least one function of the Nf1 tumor suppressor is to antagonize the accumulation of cAMP and the expression of cyclin D1 in Schwann cells. Thus a $G_{1}$ phase-specific protein, cyclin D1, accounts for two salient features of Schwann cell growth control: the promitotic response to cAMP and the antimitotic response to the Nf1 tumor suppressor.

Key words: Schwann cell; platelet-derived growth factor; cAMP; cyclin D1; cell cycle; neurofibromatosis

Schwann cells. A functional role for this neuregulin-induced cAMP is indicated by the observation that protein kinase A antagonists block the mitogenic action of neuregulin (Kim et al., 1997a,b; Howe and McCarthy, 2000).

How does cAMP cooperate with growth factors to promote Schwann cell growth? In adult tissues and in developing embryos, growth factor receptor genes are expressed conditionally in response to physiological, environmental, and temporal cues. Conceivably, cAMP could function at the very onset of growth factor action by stimulating expression of growth factor receptors. Indeed, it has been shown that the receptor for PDGF is dramatically upregulated by cAMP in cell culture (Weinmaster and Lemke, 1990). However, an alternative function for cAMP is suggested by recent studies on the role of D-type cyclins in the control of Schwann cell growth. Using mice with targeted disruption of cyclin genes, it has been shown that cyclin D1 is specifically required for the growth of mature Schwann cells (Kim et al., 2000). The upregulation of cyclin D1 requires either a complete mitogen (neuregulin) or an incomplete mitogen (PDGF) in combination with forskolin.

In studies described here, we localize the interaction between PDGF and cAMP. We show here that cAMP acts downstream rather than upstream of growth factor receptor expression and that its function is to sustain high levels of cyclin D1 expression as Schwann cells progress through the $G_{1}$ phase of the cell cycle. We show, in addition, that at least one function of the Nf1 tumor suppressor is to antagonize the accumulation of cAMP and the expression of cyclin D1 in Schwann cells.

\section{MATERIALS AND METHODS}

Antibodies. Antibodies to cyclin D1 (72-13G, monoclonal), cyclindependent kinase 4 (cdk4) (H-303, polyclonal), and PDGF $\beta$ receptor (958, polyclonal) were obtained from Santa Cruz Biotechnology (Santa Cruz, CA) and used at a dilution of 1:500 in Western blot analysis. For 
immunofluorescence, the monoclonal antibody to bromodeoxyuridine (BrdU) (Boehringer Mannheim, Indianapolis, IN) was used at a dilution of 1:50.

Primary rat Schwann cell culture. Schwann cells were prepared from sciatic nerves of newborn rats (1-2 d old) as described previously (Brockes et al., 1979). For routine culture, the medium was DMEM with $10 \%$ fetal bovine serum (FBS), supplemented with neuregulin $(10 \mathrm{ng} / \mathrm{ml})$ and forskolin $(2 \mu \mathrm{M})$ (Schwann cell growth medium). Cells between passages 2 and 4 were used in all experiments described in the text. For experiments involving PDGF (the BB homodimer; Upstate Biotechnology, Waltham, MA) and forskolin (Calbiochem, San Diego, CA), the Schwann cell cultures were shifted to PDGF-free DMEM prepared as previously described (Stiles et al., 1979).

$\left[{ }^{3} H\right]$ thymidine incorporation. Quiescent Schwann cells were plated onto 96-well culture dishes in DMEM with $10 \%$ FBS at a density of $1.5 \times$ $10^{4}$ cells per well. Two days after plating, the cultures were shifted to PDGF-free medium; $18 \mathrm{hr}$ later, $\left[{ }^{3} \mathrm{H}\right]$ thymidine $(5 \mu \mathrm{Ci} /$ well $)$ was added, and cells were incubated for another $24 \mathrm{hr}$. DNA synthesis was measured by monitoring the incorporation of $\left[{ }^{3} \mathrm{H}\right]$ thymidine into trichloroacetic acid (TCA)-insoluble material by liquid scintillation counting as described (Nordlund et al., 1992).

Immunoprecipitation and Western blot analysis. To prepare cell lysates, 90-95\% confluent rat Schwann cells on $60 \mathrm{~mm}$ plates were washed twice in PBS, then lysed in $300 \mu \mathrm{l}$ of ice-cold lysis buffer $(50 \mathrm{~mm}$ Tris $\mathrm{HCl}, \mathrm{pH}$ $7.4,1 \% \mathrm{NP}-40,0.25 \%$ sodium deoxycholate, $150 \mathrm{~mm} \mathrm{NaCl}, 1 \mathrm{~mm}$ EGTA, $10 \mu \mathrm{g} / \mathrm{ml}$ leupeptin, $2 \mu \mathrm{g} / \mathrm{ml}$ aprotinin, $1 \mathrm{mM}$ PMSF, and $0.5 \mathrm{~mm}$ sodium orthovanadate). Lysates were cleared by centrifugation at $14,000 \mathrm{rpm}$ for $15 \mathrm{~min}$ in the cold, and the protein concentration of the supernatants was determined according to specifications of the manufacturer (Bio-Rad, Hercules, CA). For Western blot analysis, 50-70 $\mu \mathrm{g}$ of Schwann cell lysates were size-fractionated on $10 \%$ SDS-polyacrylamide gels, transferred onto polyvinylidene difluoride membrane, and immunoblotted with cyclin D1, PDGF $\beta$ receptor, or phosphotyrosine (4g10) antibodies. After incubation with horseradish peroxidase-conjugated secondary antibodies, the protein bands were visualized by enhanced chemiluminescence. For immunoprecipitation, $500 \mu \mathrm{g}$ of Schwann cell lysates were incubated with $0.6 \mu \mathrm{g}$ of anti-PDGF $\beta$ receptor antibody for $3 \mathrm{hr}$ at $4^{\circ} \mathrm{C}$, then incubated with $50 \mu \mathrm{l}$ of Sepharose A beads for $1 \mathrm{hr}$. Beads were washed five times in the lysis buffer, and proteins bound to beads were fractionated on 7\% SDS-polyacrylamide gels and subjected to Western blot analysis.

Schwann cell infection. Mouse cyclin D1 cDNA was cloned into the pNIT retroviral vector (a gift from Dr. Fred H. Gage, Salk Institute) under the control of a tetracycline-suppressible promoter (Gossen and Bujard, 1992). Retroviruses were generated by transiently transfecting 293 GPG packaging cells as described (Ory et al., 1996). Quiescent primary rat Schwann cells were plated on poly-L-lysine-coated six-well plates at a density of 100,000 cells per well in DMEM-10\% FBS, then placed in Schwann cell growth medium the next day. Eighteen to $20 \mathrm{hr}$ later, which corresponds to the time of Schwann cell S-phase entry, the growth medium was removed. A 1:1 mixture of Schwann cell growth medium and viral supernatant with a total volume of $1 \mathrm{ml}$ containing 8 $\mu \mathrm{g} / \mathrm{ml}$ polybrene was added to Schwann cells. Twenty-four hours later, the viral medium was removed, and $2 \mathrm{ml}$ of fresh Schwann cell growth medium containing $1 \mu \mathrm{g} / \mathrm{ml}$ tetracycline and $200 \mu \mathrm{g} / \mathrm{ml} \mathrm{G} 418$ was added. Cells remained under G418-drug selection for 10-14 d, or until all of the uninfected cells were dead in the presence of neomycin (G418). At the end of the selection period, drug-resistant Schwann cell clones were pooled and analyzed.

For proliferation assay, cells were plated on poly-L-lysine-coated glass coverslips at a density of 60,000 cells per coverslip in DMEM with $10 \%$ FBS supplemented with tetracycline. The next day, coverslips were washed three times in PBS and placed in tetracycline-free media. Eighteen hours later, the coverslip cultures were placed in PDGF-free medium and treated as indicated. After $24 \mathrm{hr}$, BrdU was added to the medium. Cells were cultured for $24 \mathrm{hr}$ and then fixed in cold methanol for $10 \mathrm{~min}$, rehydrated in PBS for $3 \mathrm{~min}$, and treated with $2 \mathrm{~N} \mathrm{HCl}$ for $15 \mathrm{~min}$ at $37^{\circ} \mathrm{C}$. Cells were washed three times in borate buffer over a $10 \mathrm{~min}$ period, then washed three times in PBS in the same manner. A monoclonal BrdU antibody was applied in 5\% normal goat serum in PBS for $1 \mathrm{hr}$ at room temperature. Cy2-conjugated goat anti-mouse secondary antibody was added for $1 \mathrm{hr}$, and before mounting, cells were incubated with $4^{\prime}, 6^{\prime}$-diamidino-2-phenylindole (DAPI) for $1 \mathrm{~min}$ to visualize the nuclei.
(A)

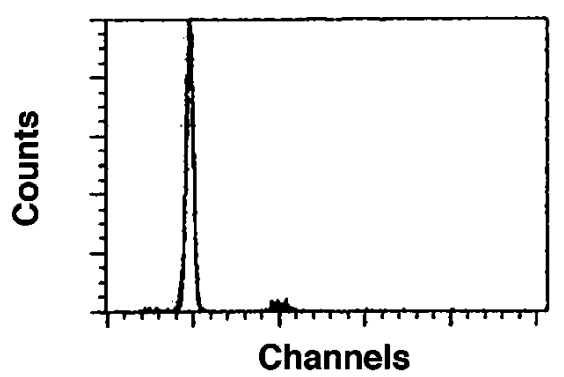

(B)

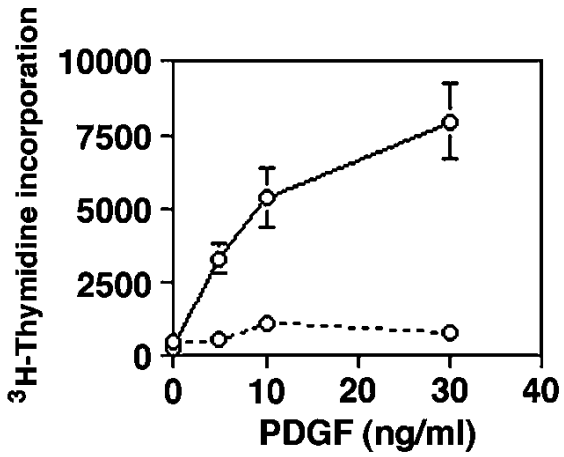

(C)

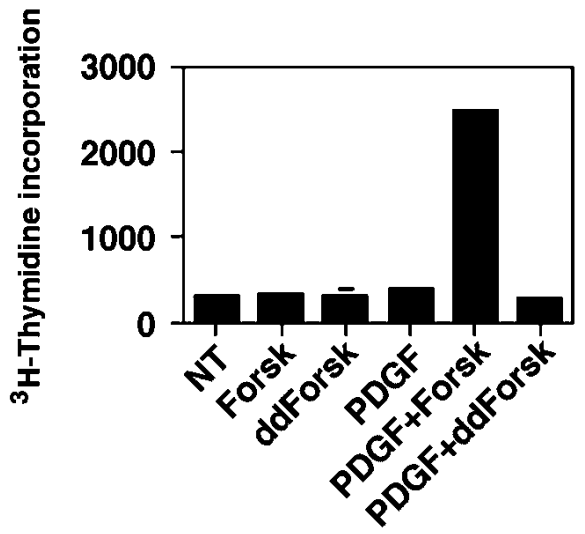

Figure 1. PDGF and forskolin interact synergistically to promote Schwann cell growth. $A$, Growth arrest in PDGF-free medium. Growing Schwann cells were transferred to PDGF-free medium, cultured for $2 \mathrm{~d}$, and then processed for fluorescence-activated cell sorter analysis. Most of the cells $(>95 \%)$ are growth-arrested at the $G_{1}$ phase indicated by the first peak. Less than $4 \%$ of cells show accumulation at the $\mathrm{G}_{2} / \mathrm{M}$ phase. $B$, Induction of growth by PDGF plus forskolin. Quiescent Schwann cells in PDGF-free medium were stimulated with PDGF (5-30 $\mathrm{ng} / \mathrm{ml})$ in either the presence (solid line) or absence (dotted line) of forskolin $(5 \mu \mathrm{M})$. Proliferative responses were monitored by the uptake of $\left[{ }^{3} \mathrm{H}\right]$ thymidine. $C$, Synergism between PDGF and forskolin is dependent on the activation of adenylate cyclase. Quiescent Schwann cells in PDGF-free medium were stimulated with PDGF in combination with either forskolin (Forsk) or dideoxy forskolin (ddForsk), a forskolin analog that lacks the ability to stimulate adenylase cyclase activity. Each error bar represents the mean \pm SD from three independent wells. In some cases, the magnitude of error is too small to be seen on the scale used in this figure. NT, No treatment.

Intracellular cAMP measurement. Cells were washed in HBSS and lysed in $200 \mathrm{ml}$ of ice-cold $6 \% \mathrm{TCA} / 4 \mathrm{~mm}$ EDTA by freeze-thaw cycling four times through liquid nitrogen and a $37^{\circ} \mathrm{C}$ water bath. TCA-insoluble material was scraped and harvested for $15 \mathrm{~min}$ at $14,000 \mathrm{rpm}$ in a clinical centrifuge. TCA supernatants were collected and dried by speed-vacuum centrifugation. The cAMP content of the dried supernatant material was measured with a cAMP radioimmunoassay kit according to the instructions of the manufacturer (Amersham, Arlington Heights, IL). The pellets from TCA precipitation were used for protein determination. 
(A)

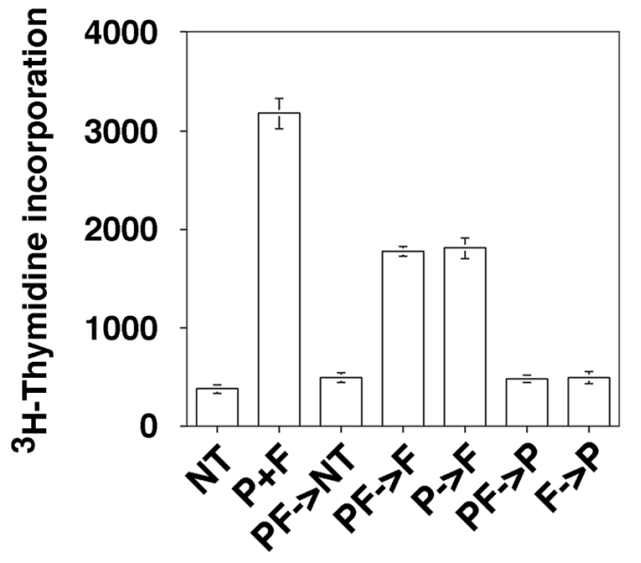

(B)

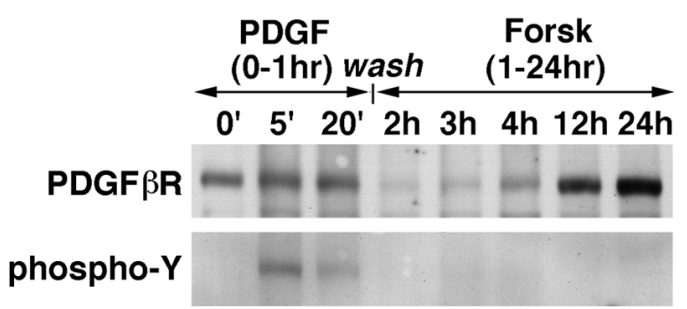

Figure 2. cAMP functions lie downstream of PDGF receptor activation. $A$, Order-of-addition experiments. Growth-arrested Schwann cells in PDGF-free medium were exposed to $30 \mathrm{ng} / \mathrm{ml}$ PDGF $(P)$ or $5 \mu \mathrm{M}$ forskolin $(F)$, or both, for $1 \mathrm{hr}$. The culture medium was then removed. Cell monolayers were washed with PBS and then incubated continually in fresh medium supplemented with additional PDGF, forskolin, or no treatment $(N T)$ as indicated for $48 \mathrm{hr}$. Cell growth was measured by the amount of $\left[{ }^{3} \mathrm{H}\right]$ thymidine incorporation. Each error bar represents the mean $\pm \mathrm{SD}$ from three independent wells. $B$, Immunoblot assay for activation state of PDGF $\beta$ receptors. Schwann cells were primed with PDGF for $1 \mathrm{hr}$, washed, and then incubated in forskolin-supplemented medium for $24 \mathrm{hr}$. At timed intervals during the priming period and subsequent forskolin incubation, cell lysates were prepared and immunoprecipitated using PDGF $\beta$ receptor antibody. Immunoprecipitates were then subjected to immunoblot analysis using either a PDGF $\beta$ receptor antibody or a phosphotyrosine antibody. PDGF $\beta$ receptor activation within Schwann cells is seen 5 min after PDGF treatment.

\section{RESULTS}

\section{PDGF and forskolin interact synergistically to promote} Schwann cell growth

To study PDGF-mediated Schwann cell growth, we needed a PDGF-free basal medium for cell culture. Because clotted blood serum, the conventional supplement for tissue culture medium, contains PDGF, we used human platelet-poor plasma (PPP), the product of unclotted blood, as our medium supplement (Stiles et al., 1979). When Schwann cells are cultured in PDGF-free medium, they become growth-arrested with a diploid $\left(\mathrm{G}_{1}\right)$ content of DNA (Fig. 1 $A$ ). PDGF and forskolin interact synergistically to promote Schwann cell growth (Fig. 1B). Dideoxy forskolin, a forskolin analog that lacks the ability to simulate adenyl cyclase, fails to synergize with PDGF (Fig. 1C).

\section{cAMP functions lie downstream of PDGF receptor activation}

Starting from growth arrest in PDGF-free medium, the lag time between the addition of PDGF/forskolin and the onset of the $\mathrm{S}$ phase is $\sim 20 \mathrm{hr}$ (Kim et al., 2000). However, as shown in Figure $2 A$, it is not necessary for the PDGF to be present continually throughout this $20 \mathrm{hr}$ lag time for growth to occur. Even very

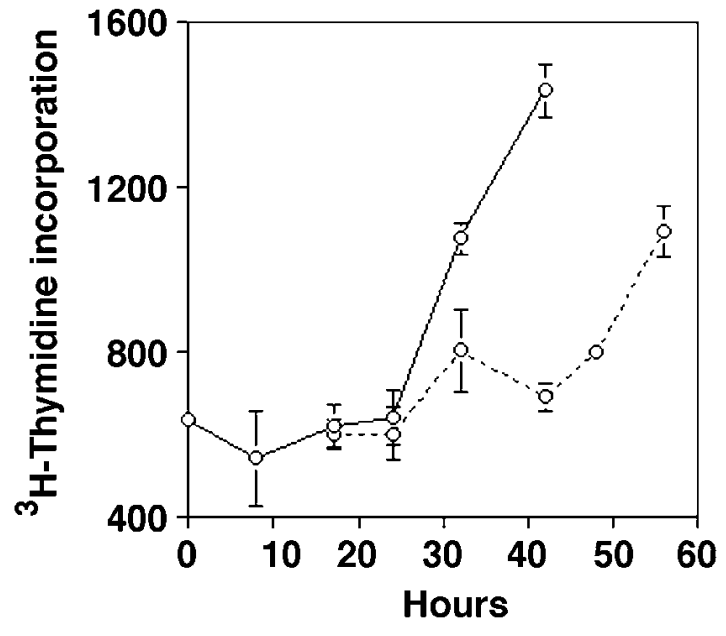

Figure 3. Forskolin initiates progression through $\mathrm{G}_{1}$ in Schwann cells that have been exposed to PDGF. Schwann cells were "primed" with a 1 hr exposure to PDGF. PDGF was then removed, and the cultures were placed in PDGF-free medium. Forskolin was added either immediately (solid line) or after a $17 \mathrm{hr}$ lag period in PDGF-free medium (dotted line). Onset of DNA synthesis was determined by measuring $\left[{ }^{3} \mathrm{H}\right]$ thymidine incorporation at timed intervals after PDGF treatment. Delaying the addition of forskolin to PDGF-primed cells delays the onset of DNA synthesis by a corresponding time. Each error bar represents the mean \pm $\mathrm{SD}$ from three independent wells.

short (1 hr) exposures to PDGF are sufficient to stimulate DNA synthesis, provided the cultures are incubated with forskolin after PDGF treatment ( $\mathrm{PF} \rightarrow \mathrm{F}, \mathrm{P} \rightarrow \mathrm{F}$ ). Unlike PDGF, forskolin is required continually throughout the $20 \mathrm{hr}$ lag period for growth to occur. Other permutations of the PDGF/forskolin order of addition $(\mathrm{PF} \rightarrow \mathrm{P}, \mathrm{F} \rightarrow \mathrm{P}$ ) do not result in Schwann cell growth. Immunoblot analysis (Fig. $2 B$ ) shows that PDGF receptors are activated quickly, but transiently, by a $1 \mathrm{hr}$ treatment with PDGF. The immunoblot assays show also that prolonged ( $<12 \mathrm{hr})$ exposure to forskolin stimulates the expression of additional PDGF receptors, confirming previous observations (Weinmaster and Lemke, 1990). However, this delayed upregulation of PDGF receptor protein is irrelevant to the mitotic action of forskolin as shown by the order-of-addition experiments (Fig. 2A) and by additional experiments below.

\section{Forskolin initiates progression through $\mathbf{G}_{1}$ in Schwann cells that have been exposed to PDGF}

Transient exposure to PDGF renders fibroblast cells "competent" to replicate their DNA and divide. However, PDGF-treated fibroblasts do not begin progressing through the $G_{1}$ phase of the cell cycle toward the $\mathrm{S}$ phase until they are exposed to insulin-like growth factor (Stiles et al., 1980). Does transient exposure to PDGF render Schwann cells competent to respond to cAMP? Schwann cells were exposed transiently ( $1 \mathrm{hr})$ to PDGF. Forskolin was then added either immediately or after a time delay of 17 hr. As shown in Fig. 3, delaying the addition of forskolin to PDGF-treated Schwann cells delays the onset of replicative DNA synthesis by a corresponding time. The lag time to the $\mathrm{S}$ phase remains constant when forskolin treatment is delayed, showing that activated PDGF receptors regulate a very early event in the cell cycle located some $20 \mathrm{hr}$ before the $\mathrm{G}_{1} / \mathrm{S}$ phase boundary. Forskolin is needed for PDGF-treated Schwann cells to initiate their movement through the $G_{1}$ phase of the cell cycle toward the $\mathrm{S}$ phase. Thus, in accord with jargon coined years ago to describe the mitogenic response of fibroblast cells to serum growth factors, 

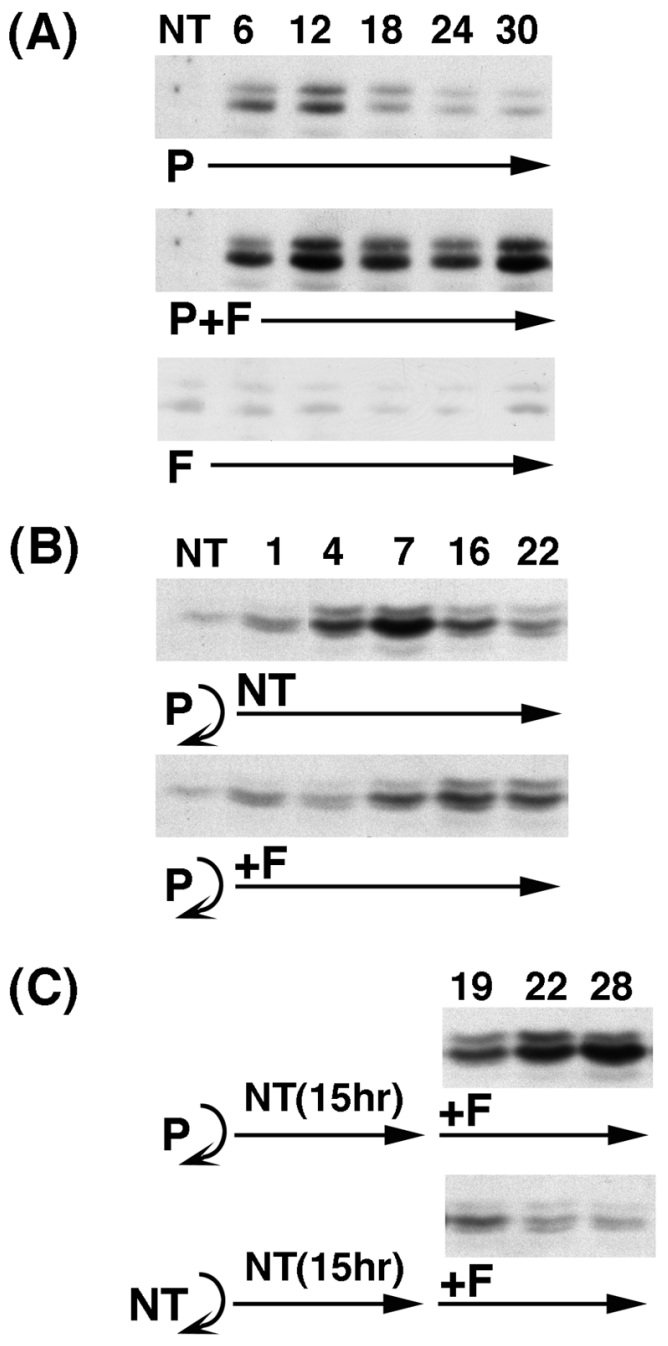

Figure 4. Forskolin regulates cyclin D1 in PDGF-primed Schwann cells. $A$, Continous exposure to PDGF $(P)$ and/or forskolin $(F)$. PDGF (30 $\mathrm{ng} / \mathrm{ml})$, forskolin $(5 \mu \mathrm{M})$, or PDGF + forskolin were added to Schwann cells that had been growth-arrested in PDGF-free medium. At timed intervals $(6,12,18,24$, and $30 \mathrm{hr})$, samples were harvested, and cyclin D1 protein was monitored by immunoblot. $N T$, No treatment. $B$, PDGF priming followed by immediate addition of forskolin as above, except that Schwann cells were primed with PDGF for $1 \mathrm{hr}$. After removal of PDGF, the medium was supplemented immediately with forskolin or left untreated. $C$, PDGF priming followed by delayed addition of forskolin as above, except that Schwann cells were primed with PDGF for $1 \mathrm{hr}$ or not primed $(N T)$. After the removal of PDGF, all cells were incubated in serum-free DMEM for $15 \mathrm{hr}$ before the addition of forskolin.

PDGF treatment renders Schwann cells competent to respond to cAMP and begin transit through the $\mathrm{G}_{1}$ phase of the cell cycle.

\section{Forskolin regulates cyclin D1 in PDGF-primed Schwann cells}

The order-of-addition experiments shown in Figures 2 and 3 show that the promitotic functions of cAMP follow, rather than precede, the activation of PDGF receptors. Moreover, the data localize the functions of cAMP to the $G_{1}$ phase of the cell cycle. These observations led us to search for other mechanisms by which forskolin could cooperate with PDGF during transit through $G_{1}$. Recent studies on mouse strains with targeted disruption of D-type cyclin genes show that the mitogenic response of mature Schwann cells is strictly dependent on expression of

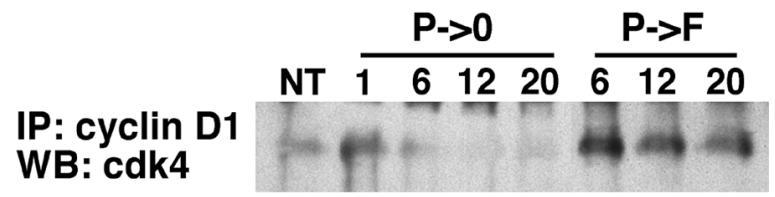

Figure 5. Amount of cyclin D1-associated cdk4 correlates with the cyclin D1 protein levels. Schwann cells were primed with PDGF for $1 \mathrm{hr}$. After removal of PDGF, cells were left untreated $(\mathrm{P} \rightarrow \mathrm{NT})$ or treated with forskolin $(\mathrm{P} \rightarrow \mathrm{F})$. Cells were harvested at 1, 6, 12, or $20 \mathrm{hr}$ as indicated, and samples were subjected to immunoprecipitation using cyclin D1 antibody followed by cdk4 immunoblot.

cyclin D1 (Kim et al., 2000). The experiments summarized in Figure 4 show that cyclin D1 expression patterns echo the PDGF/ forskolin phenomenology presented in Figures 2 and 3.

Figure $4 A$ shows that PDGF and forskolin interact synergistically to promote the expression of cyclin D1 during the $G_{1}$ phase of the cell cycle. As shown, forskolin treatment alone has no effect on cyclin D1 expression. PDGF treatment alone generates only a transient increase in cyclin D1 expression, even when the PDGF is present continually in the cell culture medium. However, PDGF and forskolin together induce an upregulation of cyclin D1 that is sustained throughout the $G_{1}$ phase of the cell cycle and into the $\mathrm{S}$ phase.

As shown in Figure $4 B$, forskolin sustains the expression of cyclin D1 in Schwann cells that have been rendered competent by transient ( $1 \mathrm{hr}$ ) exposure to PDGF. Moreover, as shown in Figure $4 C$, PDGF-treated, competent Schwann cells can respond, at a delayed time, to forskolin by upregulation of cyclin D1. In experiments comparable with those shown in Figure 4, we observe that the amount of cdk4 also correlates with the cyclin D1 protein levels (Fig. 5). Together, these observations suggest that the synergistic relationship between PDGF and forskolin might reflect the ability of forskolin to initiate or sustain the expression of cyclin D1 in Schwann cells after exposure to PDGF.

\section{Ectopic expression of cyclin D1 eliminates the requirement for forskolin in PDGF-treated Schwann cells}

To determine whether there is a functional relationship between cAMP and cyclin D1, we used a retrovirus expression vector to introduce an ectopic cyclin D1 gene into primary Schwann cell cultures. In preliminary studies, we found that constitutive expression of an ectopic cyclin D1 gene was toxic to Schwann cells, an observation previously noted in various cell types (Kranenburg et al., 1996). To circumvent this problem, a tetracyclinerepressible promoter in our vector allowed us to restrict expression of the ectopic cyclin D1 gene to a defined temporal window.

As shown in Figure $6 A$, Schwann cells that express ectopic cyclin D1 show a mitogenic response to PDGF alone. By contrast, Schwann cells infected with a control retrovirus show no growth response to PDGF alone, as noted in other experiments (Figs. 1-3). It should be noted that a significant fraction of the Schwann cells expressing ectopic cyclin D1 divide, even in the absence of PDGF treatment. This is perhaps to be expected because the retrovirus expression vector creates a sustained pattern of cyclin D1 expression (Fig. 6B) comparable with that generated by the combination of PDGF and forskolin (Fig. 4A). However, quantitative analysis indicates that the combination of PDGF and ectopic cyclin D leads to a 1.9-fold increase in Schwann cell proliferation relative to ectopic cyclin D alone $(p<0.0001)$. 

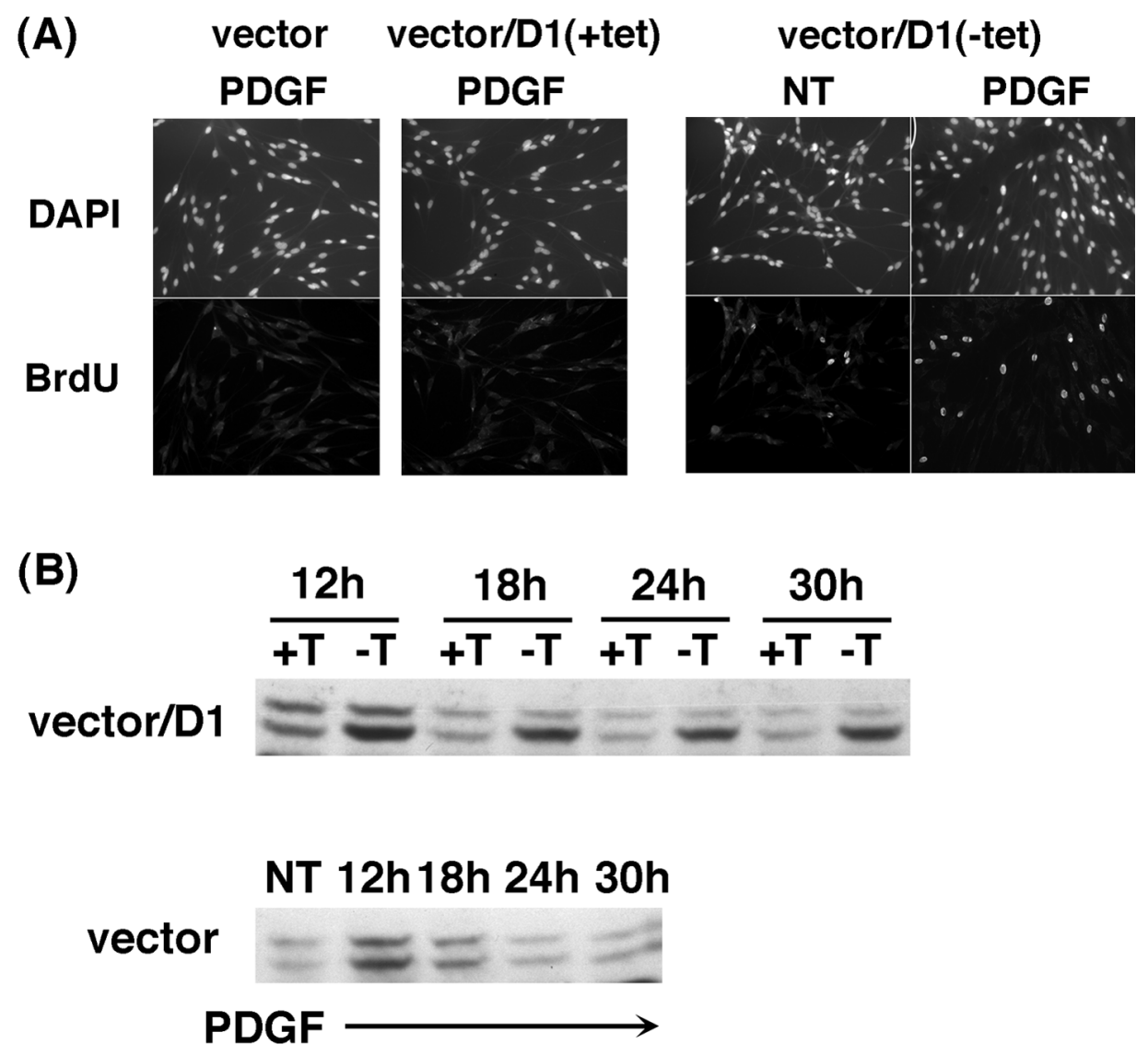

Figure 6. Ectopic expression of cyclin D1 eliminates the requirement for forskolin in PDGF-treated Schwann cells. $A$, Proliferative responses. Schwann cells were infected with control retrovirus (vector) or with retrovirus encoding cyclin D1 under the control of tetracycline repressible promoter (vector/D1). Tetracycline was removed from the medium to induce cyclin D1 expression, and cells were stimulated with PDGF. Immunostaining with a BrdU antibody was used to monitor growth response of Schwann cells, and individual nuclei were visualized by DAPI staining. $B$, Tetracylcine-regulated cyclin D1 expression. Top, Vector/D1-infected Schwann cells were cultured in PDGF-free medium. The tetracycline block $(+T)$ was removed $(-T)$. At timed intervals, lysates were prepared and immunoblotted for cyclin D1. Bottom, In a parallel experiment, Schwann cells infected with the control retrovirus vector were incubated with PDGF alone $(30 \mathrm{ng} / \mathrm{ml})$. At timed intervals, lysates were prepared and immunoblotted for cyclin D1.

\section{The Nf1 gene product antagonizes cAMP and cyclin D1 expression in Schwann cells}

Cyclin D1 is a proto-oncogene activated via overexpression in various types of human tumors (Hunter and Pines, 1994). It is not known whether there is a direct link between aberrant expression of cyclin D1 and Schwann cell tumorigenesis. However, loss-offunction mutations in the neurofibromatosis 1 (NF1) locus have been linked to Schwann cell tumorigenesis in humans (Skuse et al., 1989; Glover et al., 1991; Legius et al., 1993). Recent studies in Drosophila provide evidence that links the loss of $n f 1$ to abnormal regulation of the cAMP-PKA pathway (Guo et al., 1996; The et al., 1997). Therefore, we examined the effect of Nf1 loss on cAMP regulation in Schwann cells. As shown in Figure $7 A$, Schwann cells isolated from $N f 1$ null mice show a threefold increase in the level of intracellular cAMP relative to cells from wild-type mice. Schwann cells isolated from Nf1 heterozygous mice exhibited an intermediate level of cAMP. As shown in Figure $7 B$, the elevated levels of cAMP observed in the Schwann cells from $N f 1$ null mice correlate with a significant gain in the expression levels of cyclin D1. All of the cAMP/cyclin D1 measurements shown in Figure 7 are taken from Schwann cells cultured in growth factor-free medium. Collectively, these observations suggest that one function of the $N f 1$ tumor suppressor is to antagonize the accumulation of cAMP and the expression of cyclin D1 in Schwann cells.

\section{DISCUSSION}

Protein kinase A activity is required for Schwann cell growth. The requirement for protein kinase A function is unmasked by a broad range of incomplete Schwann cell growth factors. These agents (which include basic FGF, IGF, Reg-1, and PDGF) only function effectively as Schwann cell mitogens when they are added together with cAMP or forskolin. The goal of this study was to define the role of protein kinase $\mathrm{A}$ in promoting the action of incomplete Schwann cell growth factors. A testable hypothesis was that activation of protein kinase A stimulates expression of the transmembrane tyrosine kinases that serve as surface receptors for these growth factors. Our studies confirm previous observations that PDGF receptor expression is upregulated by forskolin (Weinmaster and Lemke, 1990). However, we go on to show that the PDGF receptor content of Schwann cells is adequate for growth even before forskolin treatment. The forskolin function(s) follows, rather than precedes, the activation of PDGF receptors. In jargon coined to describe the mitogenic response of fibroblast cells to PDGF (Pledger et al., 1977), our results indicate that PDGF renders Schwann cells competent for cell growth. Forskolin initiates and sustains the "progression" of competent Schwann cells through the $G_{1}$ phase of the cell cycle toward the S phase.

Among the members of D-type cyclin, the growth of mature 
(A)

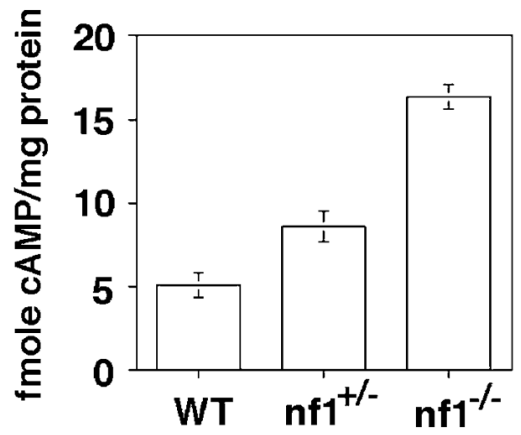

(B) Cyclin D1

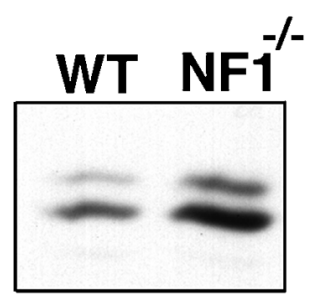

Figure 7. Constitutive cAMP and cyclin D1 in Nf1 null Schwann cells. $A$, cAMP levels in wild-type $(W T), N f 1^{+/-}$, and $N f 1^{-/-}$Schwann cells cultured in serum-free medium. $B$, Immunoblot analysis for cyclin D1 in Schwann cells derived from wild-type or $\mathrm{Nf1}^{-1-}$ mouse dorsal root ganglia. Cell lysates were prepared from Schwann cells isolated and cultured in serum-free medium as previously described (Kim et al., 1997a,b).

Schwann cells is strictly dependent on expression of cyclin D1 (Kim et al., 2000). Our data indicate that forskolin alone has no effect on cyclin D1 expression. However, forskolin sustains the expression of cyclin D1 in Schwann cells that have been exposed previously to PDGF. More striking is the observation that forskolin reinitiates the expression of cyclin D1 in PDGF-treated competent Schwann cells many hours after the removal of PDGF. Collectively, these observations argue that a prominent function for protein kinase A activity in Schwann cells is to maintain the expression of cyclin D1 after an initial mitogenic cue is delivered by a receptor tyrosine kinase. This is confirmed by demonstrating that the function of forskolin can be replaced by sustained ectopic expression of cyclin D1 in PDGF-stimulated Schwann cells. The mechanism by which forskolin sustains and re-initiates cyclin D1 expression is to be determined.

Downstream effector proteins of activated PDGF receptors include (1) src family kinases, (2) phospholipase C $\gamma$, (3) phosphatidylinositol 3 kinase, and (4) Ras (Claesson-Welsh, 1996). Which of these PDGF-modulated signal generators cooperates with cAMP to promote Schwann cell growth? Some insights may be taken from analyis of $N f 1$ null Schwann cells. The $N f 1$ gene product functions as a Ras/GAP protein (Ballester et al., 1990; Martin et al., 1990; Xu et al., 1990). Accordingly, loss-of-function Nf1 equates to gain-of-function Ras. The cAMP measurements shown in Figure 6 indicate that the loss of $N f 1$ acts to raise the intracellular levels of cAMP. Thus, the Schwann cells from Nf1 knockout mice are constitutively exposed to gain-of-function Ras and $\mathrm{CAMP}$, cues that are provided in a conditional way by PDGF and forskolin or neuregulin alone. Therefore, in Nf1 null Schwann cells, these cues result in elevated levels of cyclin D1 and may contribute to the hyperplastic growth exhibited by $N f 1$ null Schwann cells or their precursors in serum-free medium (Kim et al., 1997,a,b).

In Drosophila, nf1 null mutations lead to downregulation of adenylate cyclase activity. Moreover the $n f 1$ null phenotype can be rescued by forskolin (Guo et al., 1996; The et al., 1997). Our data show that in mammalian Schwann cells, loss-of-function Nf1 promotes, rather than inhibits, the formation of cAMP. How the loss of Nf1 acts within Schwann cells to increase cAMP remains to be determined. However, it is possible that the agonistic action of cAMP on cyclin D1 expression contributes to the development of Schwann cell tumors in patients with type 1 neurofibromatosis.

\section{REFERENCES}

Ballester R, Marchuk D, Boguski M, Saulino A, Letcher R, Wigler M, Collins F (1990) The NF1 locus encodes a protein functionally related to mammalian GAP and yeast IRA proteins. Cell 63:851-859.

Brockes JP, Fields KL, Raff MC (1979) Studies on cultured rat Schwann cells. I. Establishment of purified populations from cultures of peripheral nerve. Brain Res 165:105-118.

Brockes JP, Lemke GE, Balzer DR Jr (1980) Purification and preliminary characterization of a glial growth factor from the bovine pituitary. J Biol Chem 255:8374-8377.

Burgering BMT, Pronk GJ, van Weeren PC, Chardin P, Bos JL (1993) CAMP antagonizes p21ras-directed activation of extracelluar signalregulated kinase 2 and phosphorylation of mSos nucleotide exchange factor. EMBO J 12:4211-4220.

Claesson-Welsh L (1996) Mechanism of action of platelet-derived growth factor. Int J Biochem Cell Biol 28:373-385.

Cook SJ, McCormick F (1993) Inhibition by cAMP of ras-dependent activation of raf. Science 262:1069-1072.

Davis JB, Stroobant P (1990) Platelet-derived growth factors and fibroblast growth factors are mitogens for rat Schwann cells. J Cell Biol 110:1353-1360.

Eccleston PA, Collarini EJ, Mirsky R, Jessen KR, Richardson WD (1990) Platelet derived growth factor stimulates Schwann cell DNA synthesis. Neuroscience 2:985-992.

Glover TW, Stein CK, Legius E, Andersen LB, Brereton A, Johnson S (1991) Molecular and cytogenetic analysis of tumors in von Recklinghausen neurofibromatosis. Genes Chromosomes Cancer 3:62-70.

Gossen M, Bujard H (1992) Tight control of gene expression in mammalian cells by tetracycline-responsive promoters. Proc Natl Acad Sci USA 89:5547-5551.

Graves LM, Bornfeldt KE, Raines EW, Potts BC, Macdonald SG, Ross R, Krebs EG (1993) Protein kinase A antagonizes platelet-derived growth factor-induced signaling by mitogen-activated protein kinase in human arterial smooth muscle cells. Proc Natl Acad Sci USA 90:10300-10304.

Guo H-F, The I, Hannan F, Bernards A, Zhong Y (1996) Requirement of Drosophila NF1 for activation of adenylyl cyclase by PACAP38-like neuropeptides. Science 276:795-798.

Howe DG, McCarthy KD (2000) Retroviral inhibition of cAMPdependent protein kinase inhibits myelination but not Schwann cell mitosis stimulated by interaction with neurons. J Neurosci 20:3513-3521.

Hunter T, Pines J (1994) Cyclins and cancer. II: Cyclin D and CDK inhibitors come of age. Cell 79:573-582.

Jessen KR, Mirsky R (1992) Schwann cells: early lineage, regulation of proliferation and control of myelin formation. Curr Opin Neurobiol 2:575-581.

Kim HA, DeClue JE, Ratner N (1997a) cAMP-dependent protein kinase $\mathrm{A}$ is required for Schwann cell growth: interactions between the cAMP and neuregulin/tyrosine kinase pathways. J Neurosci Res 49:236-247.

Kim HA, Ling B, Ratner N (1997b) Nf1-deficient mouse Schwann cells are angiogenic and invasive and can be induced to hyperproliferate: reversion of some phenotypes by an inhibitor of farnesyl protein transferase. Mol Cell Biol 17:862-872.

Kim HA, Pomeroy SL, Whoriskey W, Pawlitzky I, Benowitz LI, Sicinski P, Stiles CD, Roberts TM (2000) A developmentally regulated switch directs regenerative growth of Schwann cells through cyclin D1. Neuron 26:405-416.

Kranenburg O, van der Eb AJ, Zantema A (1996) Cyclin D1 is an essential mediator of apoptotic neuronal cell death. EMBO J 15:46-54.

Legius E, Marchuk DA, Collins FS, Glover TW (1993) Somatic deletion of the neurofibromatosis type 1 gene in a neurofibrosarcoma supports a tumour suppressor gene hypothesis. Nat Genet 3:122-126.

Lemke GE, Brockes JP (1984) Identification and purification of glial growth factor. J Neurosci 4:75-83.

Livesey FJ, O'Brien JA, Li M, Smith AG, Murphy LJ, Hunt SP (1997) A Schwann cell mitogen accompanying regeneration of motor neurons. Nature 390:614-618.

Martin GA, Viskochil D, Bollag G, McCabe PC, Crosier WJ, Haubruck 
H, Conroy L, Clark R, O'Connell P, Cawthon RM, Innis MA, McCormick F (1990) The GAP-related domain of the neurofibromatosis type 1 gene product interacts with ras p21. Cell 63:843-849.

Nordlund M, Hong D, Fei X, Ratner N (1992) Schwann cells and cells in the oligodendrocyte lineage proliferate in response to a 50,000 dalton membrane-associated mitogen present in developing brain. Glia 5:182-192.

Ory DS, Neugeboren BA, Mulligan RC (1996) A stable human-derived packaging cell line for production of high titer retrovirus/vesicular stomatitis virus $G$ pseudotypes. Proc Natl Acad Sci USA 93:11400-11406.

Pledger WJ, Stiles CD, Antoniades HN, Scher CD (1977) Induction of DNA synthesis in Balb/c-3T3 cells by serum components: reevaluation of the commitment process. Proc Natl Acad Sci USA 74:4481-4485.

Raff MC, Abney E, Brockes JP, Hornby-Smith A (1978) Schwann cell growth factors. Cell 15:813-822.

Sevetson BR, Kong X, Lawrence C (1993) Increasing cAMP attenuates activation of mitogen-activated protein kinase. Proc Natl Acad Sci USA 90:10305-10309.

Skuse GR, Kosciolek BA, Rowley PT (1989) Molecular genetic analysis of tumors in von Recklinghausen neurofibromatosis: loss of heterozygosity for chromosome 17. Genes Chromosomes Cancer 1:36-41.

Stewart HJ, Eccleston PA, Jessen KR, Mirsky R (1991) Interaction between cAMP elevation, identified growth factors, and serum components in regulating Schwann cell growth. J Neurosci Res 30:346-352.

Stiles CD, Isberg RR, Pledger WJ, Antoniades HN, Scher CD (1979) Control of the Balb/c-3T3 cell cycle by nutrients and serum factors: analysis using platelet-derived growth factor and platelet-poor plasma. J Cell Physiol 99:395-405.

Stiles CD, Pledger WJ, Tucker RW, Martin RG, Scher CD (1980) Regulation of the Balb/c-3T3 cell cycle-effects of growth factors. J Supramol Struct 13:489-499.

The I, Hannigan GE, Cowley GS, Reginald S, Zhong Y, Gusella JF, Hariharan IK, Bernards A (1997) Rescue of a Drosophila NF1 mutant phenotype by protein kinase A. Science 276:791-794.

Weinmaster G, Lemke G (1990) Cell-specific cyclic AMP-mediated induction of the PDGF receptor. EMBO J 9:915-920.

$\mathrm{Xu}$ GF, Lin B, Tanaka K, Dunn D, Wood D, Gesteland R, White R, Weiss R, Tamanoi F (1990) The catalytic domain of the neurofibromatosis type 1 gene product stimulates ras GTPase and complements ira mutants of $S$. cerevisiae. Cell 63:835-841. 